Lepr Rev (1992) 63, Supplement, 77s-83s

\title{
OMSLEP as an evaluation tool
}

\section{E DECLERCQ}

If leprosy is to be controlled, those in charge of the programmes at the local, regional or global levels should be able:

- to check whether the control measures, that is the strategies and targets that have been planned, are effectively and efficiently implemented. This is the operational evaluation; and

- to evaluate whether the programme has reached its medium- or long-term objectives, that is the reduction of the problem in terms of the numbers of patients in need of the health services. That is the epidemiological evaluation.

The evaluation process should be based on the use of objective indicators. These indicators need also to be simple to allow health workers at all levels, even the most peripheral, to collect the data necessary to calculate them.

The need to use standardized indicators is evident at the national level. It is also advantageous at the regional or global level. For instance it would allow the epidemiological trend to be analysed in relation to the control strategies used locally.

From the start this has been the objective of the OMSLEP system in the recording and reporting of leprosy patients: to propose not only a set of standard indicators for the operational and epidemiological evaluation, but also a system for collecting the data necessary to calculate them.

When it was decided to create the system in 1976, the first step was to make a review of the information systems used in 78 leprosy control projects from 45 countries. This enabled a list to be drawn up of indicators whose value had been thoroughly reviewed by a group of experts. Then the data that needed to be collected were listed, and an individual patient form and two annual statistical forms designed. A booklet was published, explaining how to fill in the form, how to calculate the indicators, and how to interpret them.

From the start, the OMSLEP system was also designed to facilitate the transfer of data onto microcomputers.

In the years following its conception, a second edition of the booklet was published, with some minor modifications. In 1987 the third edition was published in order to adapt the system to evaluate MDT programmes, based on the list of 25 indicators recommended by a WHO Study Group in 1985. The design of the system remained basically unchanged, with an individual patient form, and two annual statistical forms:

- the individual patient form is a summary of the patient's clinical chart, which only takes into account the data necessary to calculate the indicators (Appendix 1);

- the detection form, which is a summary of the status at detection of all the patients 
newly detected during the year; its purpose is to help calculate the indicators dealing with incidence or detection (Appendix 2);

- the annual statistics form gives the data of all the patients who have been registered at one time or another during the year. It allows the calculation of the indicators dealing with prevalence or with the status of the patients after detection (Appendix 3).

The software for PC computers was also adapted for the evaluation of MDT programmes. At the same time it was made compatible with the requirements of ILEP.

The underlying philosophy of the system has always been to be as simple as possible, so that it could be used by polyvalent health workers at the peripheral level. It was to permit both the management of the project locally, and the monitoring of the programme at national level. At the same time, as it is based on the collection of individual patients' data, it also allows some sophisticated analyses such as cohorts or survival analyses to be carried out. This is of course particularly easy when the system is computerized.

From the information available, OMSLEP has been introduced in either its standard or in an adapted form in 54 countries at the national level. The ILOMSLEP software is also used in a number of programmes, but only in 5 countries at the national level.

The use and impact of MDT is of course among the most important aspects of leprosy control that need to be monitored. This monitoring should not pose any problem where an adequate information system exists. An attempt to monitor MDT at the global level has been made by the Department of Epidemiology of the Catholic University of Louvain in Brussels, Belgium, through the 'Leprosy Epidemiological Bulletin', which is published every 6 months.

The data are mainly collected through a standard questionnaire sent to the Ministries of Health of leprosy endemic countries. In case no information is sent by the Ministry of Health, other sources of information are also used, such as:

-ILEP and ILEP representatives at national level;

- papers published in scientific journals that deal with prevalence, case detection or MDT coverage at national level;

- the WHO Leprosy Unit at Headquarters, with whom there is a regular exchange of information.

The data requested are the following:

- total population of the country;

- year of introduction of MDT in the country;

-MDT regimens used;

- registered cases at the end of the year;

-MDT cases;

- newly detected cases during the year;

— additional MDT cases;

- completed MDT;

- cumulative MDT cases;

-cumulative completed MDT cases.

The data concerning the leprosy patients are requested by type of leprosy. These data are presented by country, WHO Region and at the global level. They are also used to calculate the following 4 indicators (Appendix 4): 
Table 1. Leprosy Epidemiological Bulletin. Last year for which the requested data were available

\begin{tabular}{|c|c|c|c|c|}
\hline & 1989 & 1988 & $\begin{array}{c}\text { Before } \\
1988\end{array}$ & $\begin{array}{c}\text { Not } \\
\text { available }\end{array}$ \\
\hline Registered cases & 92 & 47 & 30 & 5 \\
\hline MDT cases & 85 & 48 & 20 & 21 \\
\hline New cases & 73 & 51 & 23 & 27 \\
\hline Additional MDT cases & 59 & 29 & 22 & 64 \\
\hline Completed MDT & 56 & 28 & 23 & 67 \\
\hline Cumulative MDT cases & 52 & 30 & 24 & 68 \\
\hline Cumulative completed MDT cases & 53 & 44 & 24 & 53 \\
\hline
\end{tabular}

- prevalence rate;

- case-detection rate;

- proportion of patients on MDT;

- proportion of patients who have completed their treatment among the cumulative MDT cases.

The data presented in the 'Bulletin' concern 174 countries and territories. However, not all the data are available from every country. Even when they are available, the data are often not consistent. Obviously, with the exception of a number of very well-structured control programmes, the number and quality of the data available at national level are rather limited (Table 1 ).

Some possible reasons for this lack of reliable information could be:

- that there is a lack of interest from the peripheral health workers to collect information whose usefulness has not been made clear to them;

- there is no regular feedback to the periphery;

- the number of data requested is too large;

- the frequency of reporting requested is too high.

Thus there is an urgent need to redefine a very limited set of basic indicators, for which the data could be easily and reliably collected by primary health care workers and which should thus be within the capabilities of all control programmes and countries.

This limited set of indicators would be the backbone of the information system. Additional and optional information, allowing more elaborate analyses, could also be defined to be collected in specific projects according to local possibilities, and particularly for operational research.

Once this is done, the OMSLEP system could be easily adapted to provide appropriate support.

\section{Acknowledgments}

We are grateful to Claudine B Misson for her continuous efforts in the development of the OMSLEP system and its successive adaptation. We are also grateful for the services given to users in the leprosy-endemic countries. 
Appendix 1. OMSLEP individual patient form

INOIVIOUAL PATIENT FORM I.P.F.

NAME..

DEnTiFication NR

पमापID

ADRESS

DATE OF PRESENT REGistration $\square$

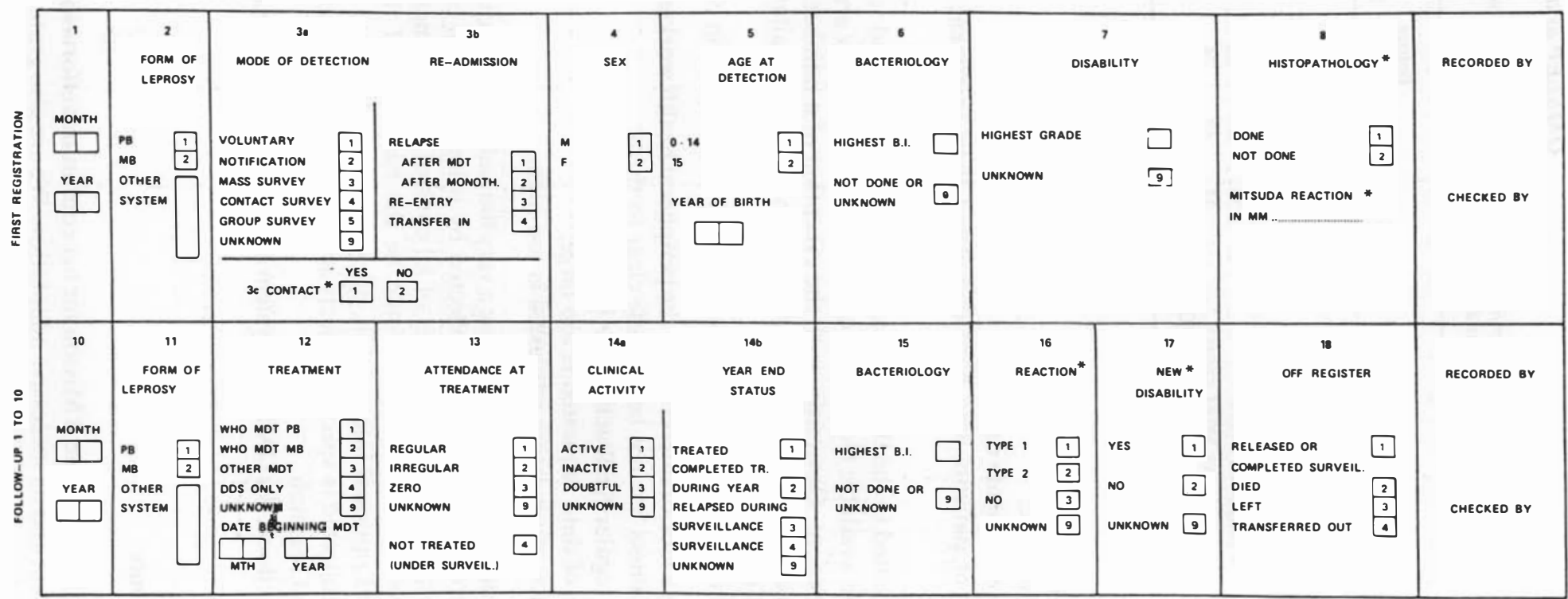

* optional 


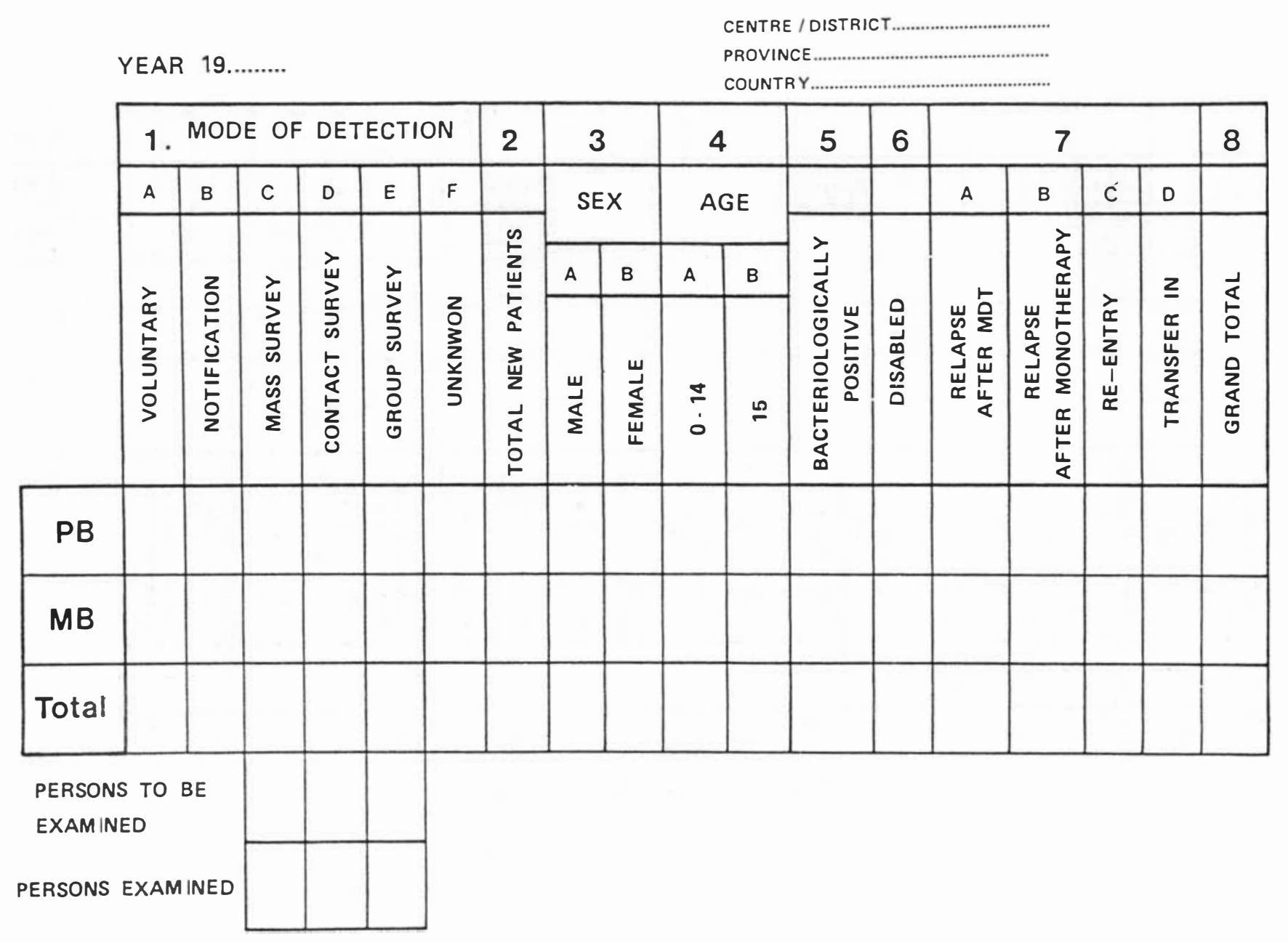


YEAR $19 \ldots . . .$.

CENTAE / DISTRICT

PROVINCE.

\begin{tabular}{|c|c|c|c|c|c|c|c|c|c|c|c|c|}
\hline 1 & 2 & 3 & OFF REGISTER & 4 & 5 & YEAR END STATUS & 6 & $\begin{array}{l}\text { ATTENDANCE AT } \\
\text { TREATMENT }\end{array}$ & 7.1CLINICAL STATUS & 7.2 CLIN. & 8.1 BACT. STATUS & $8.2 \begin{array}{l}\text { BACT. } \\
\text { SURV. }\end{array}$ \\
\hline
\end{tabular}

\begin{tabular}{|c|c|c|c|c|c|c|c|c|c|c|c|c|c|c|c|c|c|c|c|c|c|c|c|c|c|c|c|}
\hline & & & & & & & & & & & & & & & & & & & & & & & & & & & \\
\hline & & A & 8 & c & 0 & & A & B & c & 0 & $E$ & A & 8 & c & D & $E$ & $A$ & B & c & D & A & B & A & B & c & A & B \\
\hline 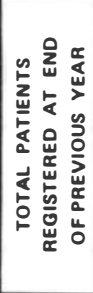 & 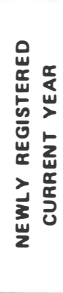 & 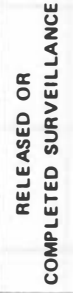 & $\stackrel{\stackrel{\mathrm{w}}{0}}{\mathrm{a}}$ & 点 & 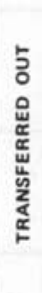 & 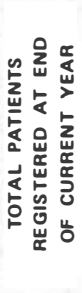 & 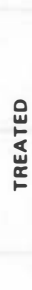 & 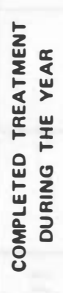 & 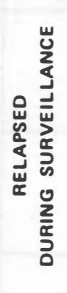 & 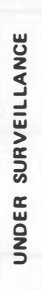 & $\begin{array}{l}\mathbf{z} \\
\mathbf{3} \\
0 \\
\mathbf{2} \\
\mathbf{2} \\
\mathbf{2}\end{array}$ & 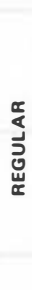 & 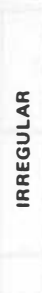 & $\begin{array}{l}\stackrel{゚}{\mathbb{x}} \\
\underset{\sim}{N}\end{array}$ & 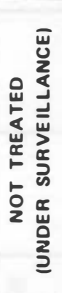 & $\begin{array}{l}\mathbf{2} \\
\mathbf{3} \\
0 \\
2 \\
\mathbf{2} \\
\mathbf{2} \\
\mathbf{2}\end{array}$ & 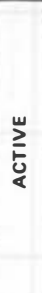 & 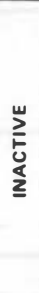 & 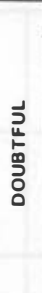 & $\begin{array}{l}2 \\
3 \\
0 \\
2 \\
\frac{2}{2} \\
3\end{array}$ & $\begin{array}{l}\text { यू } \\
\text { : }\end{array}$ & $\begin{array}{l}2 \\
0 \\
3 \\
2 \\
\frac{1}{2} \\
2 \\
0 \\
0 \\
w \\
2 \\
0 \\
0 \\
5 \\
0\end{array}$ & 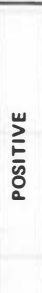 & 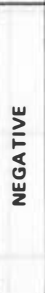 & 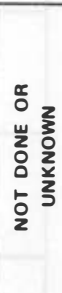 & $\begin{array}{l}\text { u山z } \\
\text { zo }\end{array}$ & 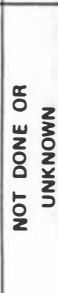 \\
\hline
\end{tabular}

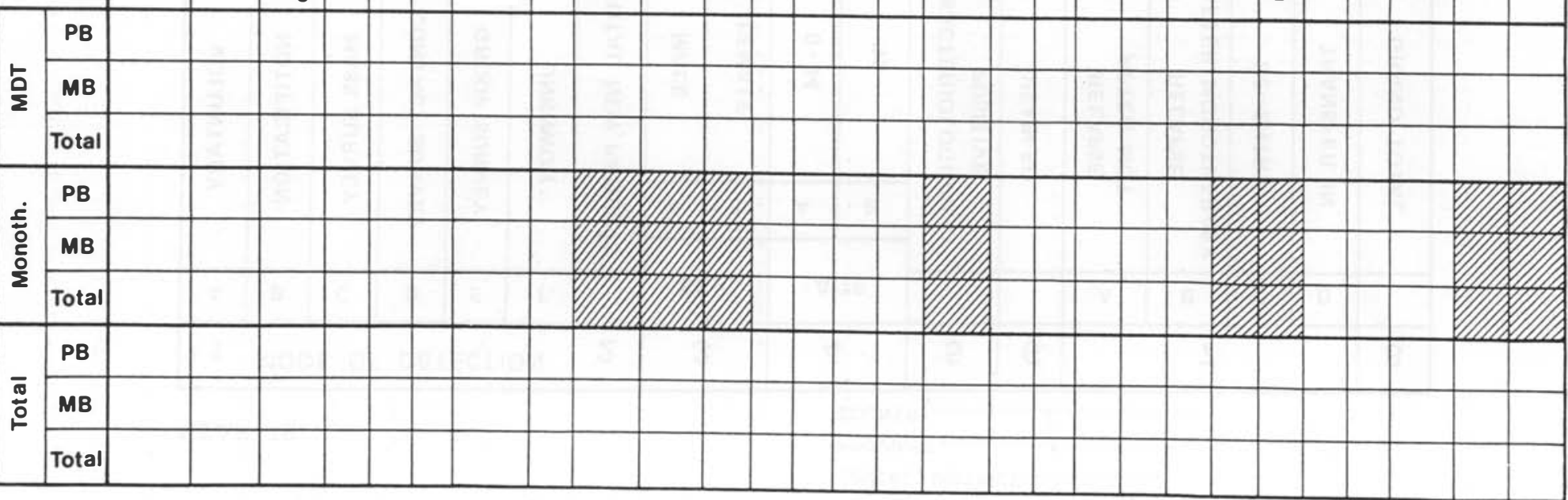

DDI NOT RELEVANT 

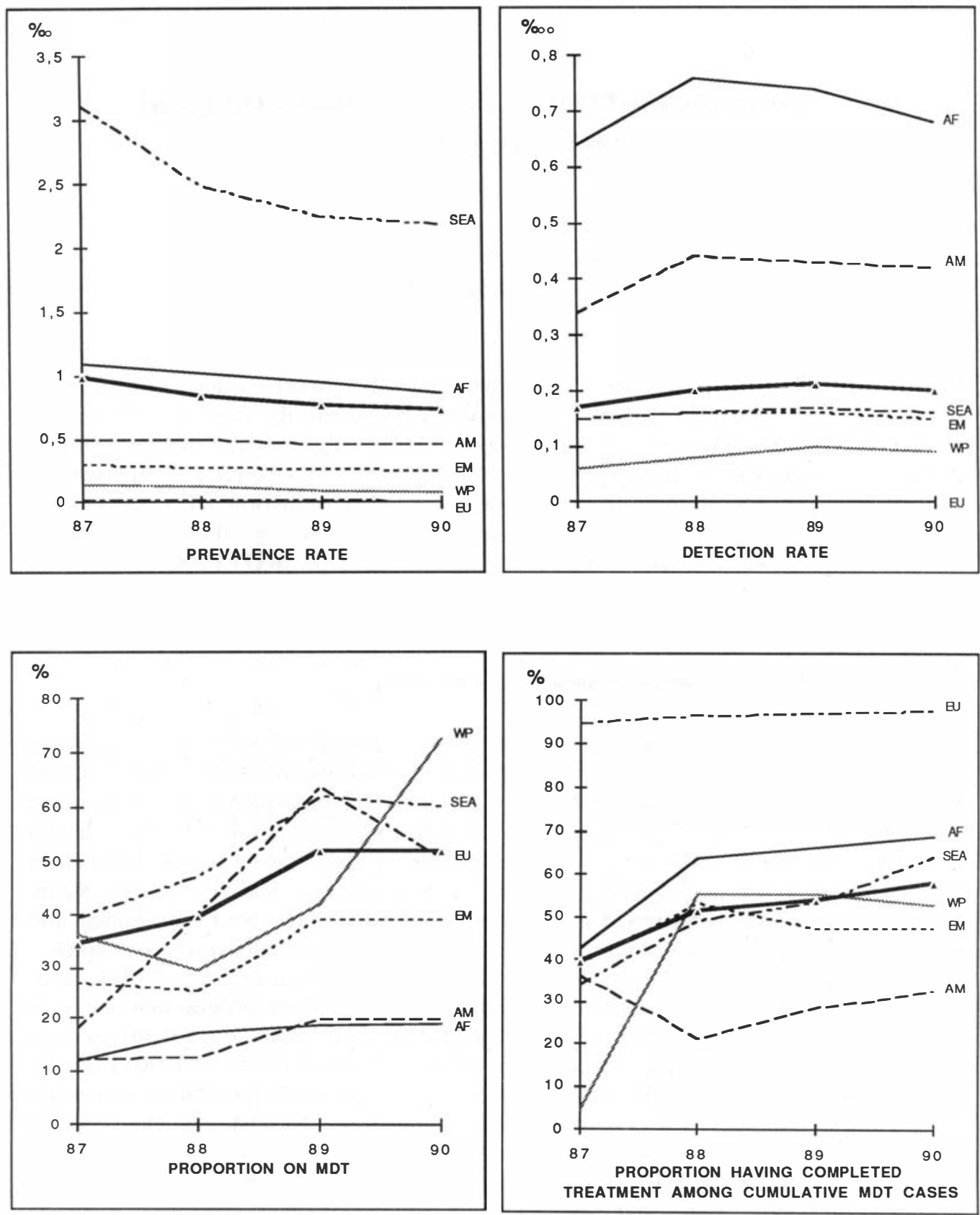

\section{$\triangle$ A All Regions}

Appendix 4. Annual trends by WHO regions (Leprosy Epidemiological Bulletin). 